\title{
Chapter 20 \\ Communication and Collaboration as Essential Elements for Mainstreaming Life Cycle Management
}

\author{
Philip Strothmann, Jodie Bricout, Guido Sonnemann, \\ and Jim Fava
}

\begin{abstract}
This chapter addresses two major challenges for mainstreaming life cycle management that are intrinsically linked: collaboration and communication. To this end it is argued that in order to radically increase the take up of life cycle based approaches in business and government, life cycle professionals need to enhance global collaboration among themselves, as well as with others and communicate to a wider set of stakeholders. The chapter makes the case that the life cycle community does not have a home, and thus currently does not exist as one coherent and clearly identifiable stakeholder. It concludes that successful communication on behalf of and with the community can only be achieved when the community is formally organized. To this end the newly established Forum for Sustainability through Life Cycle Innovation is presented as a possible way to overcome the outlined gaps and challenges.
\end{abstract}

Keywords Forum for sustainability through life cycle $\bullet$ Life cycle assessment • Life-cycle based approaches $\bullet$ Life cycle community $\bullet$ Life cycle innovation $\bullet$ Life cycle management $\bullet$ Life cycle sustainability management $\bullet$ Sustainability

\footnotetext{
P. Strothmann $(\bowtie)$

FSLCI, Berlin, Germany

e-mail: philip.strothmann@fslci.org

J. Bricout

[avniR] Platform - cd2e, Rue de Bourgogne, Base du 11/19, 62750 Loos en Gohelle, France

G. Sonnemann

University of Bordeaux, Bordeaux, France

J. Fava

thinkstep, West Chester, PA, USA
}

G. Sonnemann, M. Margni (eds.), Life Cycle Management,

LCA Compendium - The Complete World of Life Cycle Assessment,

DOI 10.1007/978-94-017-7221-1_20 


\section{Introduction}

The life cycle community has come far since SETAC and ISO first started working on standardizing methodologies in the 1990s. Tools have been developed, studies have been undertaken and some forward thinking companies and governments have integrated life cycle thinking into their policies and strategies (United Nations Environment Programme 2012).

Despite this positive development, the widespread take up of life cycle based methodologies and use of information has yet to happen. Decision makers for example still tend to simplify, zooming in on one environmental problem to find a quick fix that may have broader implications over time.

Some LCAs are also done just to tick the box for e.g. a building standard, or because a client needed it, without any further consideration. Above all, since the global economic crisis in 2008, a number of companies and governments have simply taken anything "environmental" off the agenda or reduced their efforts (Geels 2013).

\section{Missing Links}

As sustainability challenges continue to increase along with a rise in attention and global recognition of the associated issues, some life cycle based approaches, such as for example the Green House Gas Protocol or the European Commission's Product Environmental Footprint (PEF), are starting to be tested or are already applied (European Commission 2015). However, despite this positive development, life cycle based approaches are yet to be applied on a large scale to achieve tangible results. Currently, only a limited number of companies apply life cycle methodologies in their businesses to enhance the sustainability performance of their products. And due to the lack of a broad understanding of the public about life cycle approaches and methodologies, these companies are struggling to communicate their efforts in a way that resonates with the average consumer. In return, companies' efforts are currently not properly recognized by customers which reduces their efforts' value for marketing purposes. A coordinated and strong push to promote the uptake of life cycle based methodologies and concepts in companies is thus needed more than ever, coupled with an equally strong communication effort.

While the life cycle community has matured enough to address remaining methodological challenges, it is, however, still not good at explaining what it does to people who do not have a thesis in environmental chemistry or chemical engineering. Which is, however, exactly what is needed: explaining life cycle based approaches in clear terms and how they help provide solutions to many challenges facing business and government today. And it needs to be done with a global voice that takes into account modern, collaborative ways of working together, as neither individual companies nor select circles of researchers and scientist or life cycle assessment (LCA) networks are currently able to successfully drive the communication effort needed. 
According to Bjørn et al. (2013), over 100 LCA networks had been developed by 2012 , with at least seven new networks per year since 2008 . However, $40 \%$ of these networks have less than 20 members, indicating that collaboration is still happening in rather small circles. Furthermore, $68 \%$ of these networks operate at a local level and over a third are in Europe. So these small circles are mostly local, and concentrated on one continent.

Still, the positive growth of LCA networks, particularly in emerging economies over the past few years is a success of efforts undertaken, for example, by the UNEP/ SETAC Life Cycle Initiative. It was launched in 2002 and has been key in boosting collaboration around methodologies and tools since then. Similarly, SETAC has provided the LCA community with some space, which has also been used primarily to work on methodological issues. SETAC's main focus, however, remains first and foremost on issues around environmental toxicology and chemistry (SETAC 2015). And while these global players have invaluable strengths and played a great role in advancing life cycle thinking around the world (Quiros 2014), they have so far not focused on working closely with industry and businesses on establishing a global push for consumer information on life cycle aspects.

In order to be successful, such a push should also be backed and driven by the entire life cycle community, instead of a number of different stakeholders with different priorities and interests. However, as outlined before, the current state of the life cycle community is characterized by a flurry of small circles, or nodes, at a local level, and a handful of (historical) global players. The community as one clear identifiable and organized stakeholder thus currently does not exist, mostly because it has no home.

The lack of such a more organized and structured community that is visible and has its own voice has, however, implications not only from a communications perspective, but also from a collaborative point of view. As outlined above, collaboration happens mostly in small circles. Due to the discussed lack of national, regional or even global coordination efforts, synergies get lost and opportunities for collaboration are missed.

While this is mostly an issue for the community itself, the consequences are relevant beyond the community. Communication is absolutely essential to help spread the word, to inform people about the benefits of applying a life cycle perspective and enable companies to put life cycle management into practice by more easily communicating their efforts.

As shown over the past two decades, life cycle based thinking and methodologies can help to operationalize sustainability efforts and are applied by companies to identify cost and resource effective sustainability improvements and highlight them to their potential clients (Box 20.1). However, in order to mainstream LCM and thus have a tangible impact on the world, the life cycle community has to get out of the small niche in which it is currently operating. Only then it can become a powerful partner to companies and industry stakeholders and work towards effectively informing consumers on the concept and advantages of taking a life cycle perspective. 


\section{Box 20.1: A Practical Example: Renault's Efforts to Inform Their Consumers About Their Life Cycle Management Work}

To operationalize its commitment to the environment, Renault is using the life cycle management approach, focussing especially on incorporating sustainability concerns into the design and manufacturing process as well as the use phase of the car and its end-of-life treatment. In order to assess its cars' environmental performance, Renault conducts LCAs, such as, for example, for its Fluence Z.E. The LCA as well as its critical review is publicly available from Renault's website, as are brief introductions into the LCM and LCA concepts.

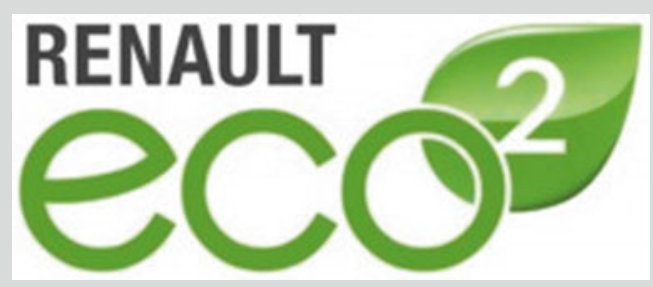

To help its consumers identify easily which of its cars have the best environmental credentials and are also the most economical to drive, Renault introduced in 2007 the Eco2 label. The label is based on Renault's environmental policy and on the analysis of the impact of their cars in the three key stages of their cars' life cycle:

- Manufacturing: Eco2 vehicles must be built in ISO 14001-certified plants

- Utilization: Eco2 vehicles must emit less than $120 \mathrm{~g}$ of $\mathrm{CO}_{2} / \mathrm{km}$

- Recycling: $7 \%$ of the plastic in Eco2 vehicles must come from recycling and Eco 2 vehicles must be $85 \%$ recyclable

Renault's application of life cycle management and life cycle assessment concepts thus helps it to provide interested customers with an internationally accepted and scientifically sound decision-making basis when making purchasing decisions (Renault 2015).

As outlined in other chapters of this book, to be successful, life cycle information needs to be applied on a significantly larger scale to have an impact in management decisions. Only then the goal to enhance sustainability efforts and eventually achieve regeneration will be successful. Essentially following the vision of "A sustainable global society where life cycle approaches are established and decision makers have fully integrated them into their regular decision making processes." To this end it is understood that life cycle approaches contribute to the overall goal of a sustainable society through providing data and knowledge for: 
- Reducing a product's resource use and emissions to the environment, and improving its social and socio-economic performance throughout its life cycle

- Enabling consumers to choose more sustainable products

- Information policy to optimize trade-offs

- Influencing and validating choices for disruptive improvements, such as new economic models or radical technology, to move towards possibilities to regenerate the system and not only be "less bad", but towards "more good"

However, for life cycle approaches to make a significant contribution to sustainability, they need to be used in a massive and systematic way, especially by companies and businesses within a framework and infrastructure provided by governments. Success will be when there is a broad understanding of the concepts around life cycle thinking by the general public and when these concepts are integrated into decisions by organizations in a systematic way through life cycle management (for example, integrated into standard design software or purchasing criteria).

\section{Moving Towards Better Collaboration and Communication to Mainstream Life Cycle Management}

As outlined before, it is now on the life cycle community to help making this vision come true. Key elements on this route will be achieved through:

- Better collaboration with each other across the globe as well as with other stakeholders

- Better communication to a wider set of stakeholders

\subsection{Improve Collaboration Among the Life Cycle Community Across the Globe}

"The community" as it is understood here is a group of people having a particular interest in common: the use of life cycle information. The community includes:

- Professionals who provide life cycle data and information to be used in internal processes or commercial or public databases

- Users of life cycle data and information as part of regular and existing decision making processes in business and governments

- Scientists and researchers who are actively working on developing new methods and approaches, methodological standards or advancements 
- Life cycle "practitioners" who apply the tools developed above in specialist consultancies, in industry (often in EHS, sustainability, R\&D departments), or in government (technical agencies like environmental agencies or policy makers)

- Life cycle advocates, who may not be able to undertake an LCA themselves, but who understand their utilization and importance

- Students in a variety of disciplines learning about how to apply life cycle thinking and approaches

Traditionally, global and local LCA networks have been dominated by academic stakeholders, but data providers, practitioners and users of life cycle data and information in industry and businesses are crucial. They are the ones who use the tools and methods to actually assess and interpret products' sustainability performance and thereby help establishing a scientifically more accurate decision-making basis for companies. As shown in Box 20.2, the LCM conference series is currently the only prominent place where companies and businesses get to exchange on their challenges and advancements. However, the LCM conference series is focused on Europe alone and organized only every 2 years, thus not well suited to facilitate a regular exchange. Other initiatives driving collaboration among the life cycle Community include:

- International life cycle networks such as the UNEP/SETAC Life Cycle Initiative and the International Society for Industrial Ecology

- Local or regional life cycle networks for practitioners, such as ACLCA in the US, ALCALA in Latin America, or ALCAS in Australia

- Life cycle conferences, such as the before-mentioned LCM, SETAC case study symposium, Ecobalance, [avniR], LCA Food, PEF World Summit

- Online collaborative platforms such as the PRe LCA discussion list and various LinkedIn groups (e.g. on $\mathrm{GaBi}$ )

- Specific workgroups targeting technical subareas of the discipline such as Social LCA, Food LCA or Toxicity and Water issues

These many "circles of collaboration" tend to be extremely dynamic and productive, and in most cases very complementary. Many work on similar issues in different geographical spaces or with different types of stakeholders. They all have their place and are an important part of nurturing this constantly evolving field. However, they do not represent the community as a coherent and clearly identifiable stakeholder, but limited possibilities for exchange.

Consequently a global effort will be needed to bring these small groups together and thereby not only facilitate knowledge sharing and the establishment of links, but more importantly create a shared sense of belonging. In the end, a community only functions if its members can identify themselves with it.

Uniting the community behind a commonly shared set of ideas, principles or perspectives is thus a key step towards creating a community as such and thus lay the ground for collaboration and co-creation. 


\section{Box 20.2: A Practical Example: Making the Bridge Between Life Cycle Management Conferences}

Since the first LCM was held in Copenhagen in 2001, this conference series has established itself as one of the leading conference series worldwide in the field of environmental, economical and social sustainability. It is now held every second year in Europe, with the seventh LCM held in Bordeaux, France.

The unique feature of the LCM conference series is developing practical solutions for the implementation of life cycle approaches into strategic and operational decision-making in business, industry and beyond. The LCM Conferences bring together international decision-makers from science, industry, NGOs and public bodies. Almost half of the participants came from the private sector in recent gatherings. In this way it is clearly differentiated and complementary to more academic events such as conferences organized by SETAC or the International Society for Industrial Ecology.

The LCM conferences provide an excellent start to transfer knowledge from the scientific world to real world applications by the private sector or governments. Whilst some uptake by the application side for the use of life cycle information is happening (e.g. building and construction, food and beverages, cars and other transports means, materials and chemicals, packaging, consumers goods, etc.), there is no real global mechanism to accelerate this awareness and uptake by the private sector and government to apply life cycle approaches as part of their normal practices. Also, given that the LCM conference series has no formal structure and is organized only every 2 years and by different host organizations, it is currently rather limited in its ability to function as the central space to facilitate ongoing and continuous exchange of ideas and challenges.

Establishing a link between a better-organized community and the LCM conference series would thus be a natural fit that could help to improve the transfer of knowledge, experience and resources. One way to achieve this could be to establish a small secretariat that could build links between LCM in Europe and other LCM related conferences taking place around the globe, such as those in China, Brazil and India, so that the conversations continue rather than being disconnected (LCM 2015).

The life cycle community will also need to actively engage and collaborate with colleagues working in related fields, such as climate change, toxicity and biodiversity, so that cooperation and collaboration result in joint efforts instead of "competing" for the same air time. In the end, life cycle concepts should be understood as a key element of the circular economy and the energy transition, and hence they should be seen as the backbone of any effort to address sustainability issues, be it climate change, resource efficiency or other issues. 
The community will also need to collaborate more closely with decision makers in industry and government to co-develop life cycle management solutions that respond to their needs, as will be demonstrated in Sect. 3.2.

\subsection{Effective Communication with a Wider Set of Stakeholders}

Widespread take up of life cycle management is impossible without a widespread understanding of what life cycle approaches are and why they are important. The audiences for this communication can be grouped into two broad categories.

\subsubsection{Anyone Looking for Information on How to Operationalize Sustainability}

Decision-makers in industry and government are key to applying life cycle thinking to operationalize sustainability in the real world. While the community develops and works directly with life cycle based tools, decision-makers in industry and government interact with life cycle based information on a different, yet from a societal perspective arguably more important level.

This audience first needs to make the step-change towards systemic, life cycle thinking in how they understand sustainability issues (including notions of arbitrage between different impact areas, and over different stages of the life cycle). They then need to have enough knowledge and understanding of what life cycle management is and how life cycle based information can be used to facilitate decisionmaking processes, to integrate it into their core activities.

\subsubsection{General Public}

As clearly demonstrated throughout the past decades, change is often only achieved if a strong push from the demand side has been established (Baron et al. 2009). To achieve this, the general public needs to understand that sustainability decisions need to be based on a systemic framework that takes into account impacts from a life cycle perspective. In return, the demand for and availability of life cycle based information will increase, once companies can communicate on their efforts without being burdened by the need to explain the concepts first.

While a growing number of consumers already consider sustainability aspects during their purchase decisions, they are increasingly confused by the vast amount of different standards, labels and other information tools (Atkinson 2014). Here it will be important to collaborate with existing programmes and initiatives which work on these issues, such as the Consumer Information Programme under the UN's 10 Years Framework on Sustainable Consumption and Production and others (CIP 2015). 
An effort to simplifying and streamline communication on product's sustainability performance based on life cycle information is thus paramount to enable consumers to better interpret different kinds of information and help them understand why taking a life cycle perspective is a key step towards operationalizing sustainability. As previously outlined, educating consumers about the advantages and necessity of taking a life cycle perspective to avoid trade-offs is also highly relevant to companies and businesses that seek to explain their efforts. Only if a general understanding of the concept is present, efforts of companies applying life cycle methodologies will be understood and welcomed. This understanding will help businesses and industry to respond to green washing claims and demonstrate real sustainability progress by implementing life cycle management (in line with Box 20.1).

In this context opinion leaders will also need to be targeted to help spread the word and generate sufficient attention. Al Gore's "An inconvenient truth", for example, helped to put the issue of global climate change on the world's agenda, at least from a communications perspective. Thanks to the film and following public appearances, the understanding of the effects of climate change has increased (Jacobsen 2011). A messaging that is neutral, scientifically sound and not driven by company-interests thus needs to be developed that could be picked up by opinion leaders to help spreading the word. As with the IPCC process, the messaging, however, will have to be backed by the life cycle community to have both credibility and relevancy on a global level.

\subsection{Audiences and Lessons Learned}

In order to effectively communicate with the different target audiences identified in Table 20.1, the life cycle community needs to agree on key messages and deliver them with a global voice, albeit adapted to local conditions. It should be noted in this context that a communication effort should focus first and foremost on decision makers in business and government to drive change. In a second step, together with successful stakeholders in the field of consumer information, the focus will need to be extended to target also the general public.

In this context, bringing together the life cycle community as a clear stakeholder is critical to establishing a global voice, but the collaboration with other stakeholders is equally important in developing communication tools and capability that resonate with people outside of the LC community.

It is also important to consider that communication is a two way street. Whilst the life cycle community needs to educate decision makers and the general public about the advantages and benefits of taking a life cycle perspective, communication also needs to work in the other direction. In this context it is crucial that the community is visible, approachable and receptive for feedback from different voices in society.

In the end it will be important to acknowledge that if societal change is the objective, it is of utmost importance to interact closely with society. Here it will be important to proactively identify opportunities to discuss sustainability challenges and support other relevant communities and actors. 
Table 20.1 Target groups and desired outcomes

\begin{tabular}{|c|c|c|}
\hline Target group & Who are they? & Desired outcomes \\
\hline $\begin{array}{l}\text { Decision makers in business } \\
\text { and public sector can be } \\
\text { reached through } \\
\text { - Cross cutting business } \\
\text { federations (e.g. chambers } \\
\text { of commerce, WGBC) } \\
\text { - Sector based business } \\
\text { federations } \\
\text { - NGOs } \\
\text { - Education centers } \\
\text { (universities and schools) } \\
\text { (future decision makers) } \\
\text { - Specialist media } \\
\text { - Funding agencies } \\
\text { bandard and certification } \\
\text { bodies }\end{array}$ & $\begin{array}{l}\text { Influential professionals } \\
\text { (middle management) and final } \\
\text { decision makers in various } \\
\text { departments: (communication, } \\
\text { sustainability, finance, product } \\
\text { development, procurement, } \\
\text { economic development, etc.) } \\
\text { Business } \\
\text { - Large businesses } \\
\text { - SMEs } \\
\text { Public sector } \\
\text { - Federal/national level } \\
\text { government } \\
\text { - Local level government } \\
\text { - Public departments }\end{array}$ & $\begin{array}{l}\text { - Develop and implement } \\
\text { LC approaches in their } \\
\text { business or policy making } \\
\text { (e.g. policy making, green } \\
\text { procurement, product } \\
\text { development) } \\
\text { - Support national LCI } \\
\text { database development and } \\
\text { management following } \\
\text { global guidance } \\
\text { - Provide case studies of } \\
\text { LC implementation } \\
\text { - Collaborate with the LC } \\
\text { community to ensure their } \\
\text { developments are well } \\
\text { aligned with needs } \\
\text { - Encourage other } \\
\text { businesses and } \\
\text { governments to engage }\end{array}$ \\
\hline $\begin{array}{l}\text { General public } \\
\text { Can be reached through } \\
\text { - NGOs } \\
\text { - Governmental programs } \\
\text { - Education centers } \\
\text { (universities and schools) } \\
\text { - General media (including } \\
\text { social) }\end{array}$ & $\begin{array}{l}\text { The general public as } \\
\text { individuals to influence their } \\
\text { behavior as consumers, } \\
\text { business stakeholders and } \\
\text { active members of civil society }\end{array}$ & $\begin{array}{l}\text { - Understand the concept of } \\
\text { taking a life cycle } \\
\text { perspective and its } \\
\text { advantages } \\
\text { - Create a market for } \\
\text { sustainable consumer } \\
\text { products } \\
\text { - Build demand for reliable } \\
\text { and transparent } \\
\text { information about life } \\
\text { cycle impacts }\end{array}$ \\
\hline
\end{tabular}

\section{Making It Happen}

For all of the reasons outlined above, it is of utmost importance for the life cycle community to become a stakeholder of its own, in order to be seen and have a global voice that is heard. This will only happen, if the community starts to structure itself in the form of a new organization. This organization should provide the actions in the following sections.

\subsection{Space to Coordinate Efforts Around the World}

Currently a number of small circles and a few international organizations exist in the life cycle space. A life cycle community organization would thus need to build close relationships with each of these existing organizations to become a central information and network hub that connects these circles and organizations again and facilitates coordination. 
This does not only apply to stakeholders as such, but also and importantly to conferences. Over the past years, a number of conference series have been organized in addition to the LCM conferences in Europe and those in key emerging economies as mentioned before ranging from EcoBalance in Japan, the Australian LCA Conference to CILCA in Latin America, InLCA in the USA and [avnir] in France. Coordination among those conferences would help not only with regards to dates, but also on content focus and international visibility, for instance by ensuring that key messages and white paper with topics relevant for LCM are spread quickly around the world.

\subsection{Space to Identify New Contacts, Apart from Conferences}

While conferences are a great place to learn about new projects, latest research and to network, they do not facilitate regular exchange. In addition, while conferences technically offer a great way to get to know new people and identify possible collaboration opportunities, the reality is different. Most participants have a pretty full schedule and have little to no time to identify and meet potentially interesting colleagues and stakeholders, outside of their already existing networks and small circles. As a consequence, a life cycle community organization would need to establish a mechanism that facilitates the process of finding interesting connections outside of conferences.

\subsection{Space to Collaborate with Colleagues}

Another important element to foster the identification of stakeholders with the community would be to establish a way that fosters and enhances collaboration. To this end a platform where new ideas could be pitched to the community or research shared would need to be put in place. Enabling interaction among community members needs to be a crucial element, as it has been established before that better ways to collaborate and co-create are needed.

\subsection{Space to Develop a Coherent Messaging}

Finally, the platform identified before should also be used to work jointly on a clear and coherent messaging, for instance on recommendations on how to put life cycle management in business practice. In this context, in order to establish a shared sense of community and belonging, a specific set of principles should be established that community members cannot only subscribe to, but have co-developed.

Above all, the community organization should seek to be as inclusive as possible to provide members with a sense of empowerment. The idea should be to enable members to speak for and on behalf of the community and thus instead of being represented, represent themselves. 


\section{Conclusion}

As outlined throughout the previous sections, two major challenges for mainstreaming life cycle management exist that are intrinsically linked: collaboration and communication. In order to radically increase the take up of life cycle based approaches in business and government, life cycle professionals need to enhance global collaboration among themselves, users of life cycle information, as well as with others and communicate to a wider set of stakeholders.

To facilitate this process, a home for the community is needed that enables it to become one coherent and clearly identifiable stakeholder but also acts as a central information and networking hub within the community. Such a home would need to respond to a variety of issues and gaps, as identified before. It would also need to make an effort to provide not only a space for collaboration and communication, but more importantly be rooted in a shared set of ideas and principles. Community members will need to be able to identify easily with the new organisation and be interested to engage with the organization and its members to jointly shape its future.

The newly established Forum for Sustainability through Life Cycle (FSLCI) is built around these considerations and will need to demonstrate in going forward that it can live up to and address the issues outlined throughout this chapter. Its success will be largely depended on its acceptance by the community, in particular those life cycle practitioners that make changes in real life by putting LCM theory outlined in the first part of this book into practice. At the moment, it remains to be seen, whether the life cycle community is ready to become a stakeholder of its own. Whether it is ready to get out of the niche, and aim for actual global change towards creating a global sustainable society, where decision makers have fully integrated life cycle management into their regular decision making processes.

Open Access This chapter is distributed under the terms of the Creative Commons Attribution Noncommercial License, which permits any noncommercial use, distribution, and reproduction in any medium, provided the original author(s) and source are credited.

\section{References}

Atkinson L (2014) Wild west' of eco-labels: sustainability claims are confusing consumers. The Guardian. http://www.theguardian.com/sustainable-business/eco-labels-sustainability-trustcorporate-government. Accessed 13 Mar 2015

Baron DP, Harjoto M, Jo H (2009) The economics and politics of corporate social performance. Graduate School of Stanford Business. Working paper no. 1993

Bjørn A, Owsianiak MI, Laurent A, Molin C, Westh TB, Hauschild MZ (2013) Mapping and characterization of LCA networks. Int J Life Cycle Assess 18:812-827

CIP (2015) The 10YFP consumer information program (CIP). www.unep.org/10yfp/Programmes/ ProgrammeConsultationandCurrentStatus/Consumerinformation/tabid/106265/Default.aspx. Accessed 28 Feb 2015

European Commission (2015) The product environmental footprint pilots. http://ec.europa.eu/ environment/eussd/smgp/pef_pilots.htm. Accessed 16 Mar 2015 
Geels FW (2013) The impact of the financial-economic crisis on sustainability transitions: financial investment, governance and public discourse. Environ Innov Soc Trans 6:67-95

Jacobsen GD (2011) The Al Gore effect: an inconvenient truth and voluntary carbon offsets. J Environ Econ Manag 61:67-78

LCM (2015) About the conference. http://lcm2015.ism.u-bordeaux1.fr/?page_id=7. Accessed 16 Mar 2015

Quiros A (2014) Communicating life cycle thinking: a worldwide application. In: Proceedings of the Indian conference on life cycle management (ILCM 2014, New Delhi, 29-30 Sept.)

Renault (2015) Environmental policy. http://group.renault.com/en/commitments/environment/ environmental-policy/. Accessed 16 Mar 2015

SETAC (2015) SETAC's mission. http://www.setac.org/?page=Mission. Accessed 16 Mar 2015

United Nations Environment Programme (2012) Greening the economy through life cycle thinking ten tears of the UNEP/SETAC life cycle initiative 